\title{
Analisis Data Produk Elektronik Di E-Commerce Dengan Metode Algoritma K-Means Menggunakan Python
}

\author{
Ainur Rahman ${ }^{1)}$, Heri Suroyo ${ }^{2)}$ \\ ${ }^{1,2)}$ Teknik Informatika, Fakultas Ilmu Komputer, Universitas Bina Darma Palembang, \\ Jalan Jendral Ahmad Yani No.3, Palembang, 30111, Indonesia. \\ Email: ainurrahman.bae@gmail.com ${ }^{1)}$, herisuroyo@ binadarma.ac.id ${ }^{2)}$
}

\begin{abstract}
Abstrak
Fokus dari peneltitian ini adalah melakukan analisis text mining pada produk elektronik yang dijual di e-commerce Shopee dengan menggunakan metode Kmeans algoritm memakai python sebagai bahasa pemrograman. Data di scraping berupa teks komentar, angka penjualan dan skor rating bintang. Data hasil dari penelitian didapatkan pada analisis teks komentar produk dengan wordcloud produk Smartphone low cost menunjukan data komentar marketplace shopee Indonesia dapat bahwa baik di smartphone low cost maupun yang high cost cenderung memiliki pola wordloud yang sama dimana kata-kata yang dominan muncul cenderung netral dan positif, sedang kata-kata yang bermakna negatif cederung tidak dominan. Sementara kata yang sering muncul yaitu barang, mantap, cepat,kirim dan bagus dengan nilai akurasi presentase sebesar 92\%. Sedangkan hasil proses wordcloud medium high cost diperoleh kata yang sering muncul ialah kata (kirim, cepat, dan bagus) dengan nilai akurasi dengan presentase $94 \%$. Serta berdasarkan hasil grafik dari proses clustering data $k$-means menunjukan bahwa angka penjualan 0 sampai 1000 mendapatkan skor rating bintang tertinggi dan penjualan dengan skor rating bintang terendah ialah antara 1500 sampai $2000 \mathrm{ke}$ atas.
\end{abstract}

Kata kunci: python, scraping, clustering.

\section{Pendahuluan (Introduction)}

Perkembangan teknologi informasi diera modernnisasi yang secara tidak langsung menuntut melakukan sesuatu dengan serba cepat dan menimbulkan dampak yang besar dan signifikan dalam kehidupan sehari-hari manusia salah satunya ialah terciptanya teknologi internet. Adapun kegiantan yang dapat dilakukan dengan pemanfaattan teknologi internet ialah melakukan proses bisnis penjualan atau pembelian berbasis online atau biasa di sebut e-commerce (Jony Wong, 2008).

Untuk mengetahui tingkat kepuasan dari setiap pelanggan terhadap kualitas produk yang dijual. Setiap e-commerce menciptakan atau membuat sebuah kolom review atau komentar yang bertujuan sebagai tempat atau wadah bagi pelanggan untuk menyampaikan dan membemberian ulasan mengenai kualitas produk yang di jual. Dimana dari setiap ulasan yang di berikan pelanggan tersebut nantinya memiliki pengaruh terhadap penjualan di e-commerce tersebut, karna setiap pelanggan yang ingin membeli sebuah produk tentunya melihat terlebih dahulu ulasan mengenai kualitas produk tersebut.

Beberapa penelitian yang relevan diantaranya text analis cluster akun shopee Indonesia memakai komentar pengguna memakai orange data mining (Sentiya et al., n.d.) dan penerapan cluster analis serta sentimen data twiter pada penilaian wisata pantai memakai Kmeans method (Syaifudin \& Irawan, 2018). Penelitian ini mencoba menganalisis ulasan atau komentar dari dua smartphone medium quality yaitu beberapa smartphone produk china dengan kualitas yang sama serta harga yang sama pada e-commerce shopee Indonesia. Adapun hasil dari dilakukannya penelitian ini adalah analisis isu pengelompokkan istilah yang lebih banyak didominasi. Dalam melakukan penelitian ini penulis menggunakan teknik analisis teks clustering dengan metode k-means. Adapun bahasa pemrograman yang digunakan dalam melakukan penelitian ini ialah python. Serta dalam proses pengumpulan data menggunakan metode scraping yang berarti pengambilan sebagian data atau konten dari suatu situs web. Dengan memafaatkan aplikasi webscraping (Indraloka \& Santosa, 2017). 


\section{Metode Penelitian (Methods)}

Analisis teks pada penelitian dilakukan dengan menarik (scrapping) data komentar dari produk yang menjadi objek penelitian di e-commerce. Text analysis artinya menyiratkan bahwa itu adalah kesalahan dari salah satu bagian awal semiotika teks, yang secara eksplisit berbicara tentang teks sebagai hasil dari penggunaan bahasa yang merupakan campuran atau seperangkat tertentu atau secara eksplisit menyangkut kerangka sintaksis atau tanda paradigmatik. lapisan yang menunjukkan indikasi atau implikasi. hubungan antara tanda-tanda figuratif atau metonimik, konten fantasi, dan filosofi di baliknya. Karena penyelidikan teks dan semiotika teks adalah bagian dari semiotika umum, aturanaturan penting yang membentuk semiotika luas juga berlaku untuk mereka. yang memiliki arti penting, meskipun unit kajian yang paling kecil adalah semiotika yang mengandung makna teks, namun teks tidak dapat dipisahkan dari tanda-tanda yang menyusunnya (Piliang, 2004).

Sementara analisis clustering dilakuan pada penelitian dengan mengambil data angka penjualan dan tingkat rating bintang yang diberikan customer. Strategi k-implies/kmeans merupakan teknik pemeriksaan informasi atau information mining strategy yang memainkan sistem demonstrasi tanpa manajemen (solo) dan merupakan salah satu teknik yang melakukan pengumpulan informasi dengan kerangka parsel. Strategi k-implies bunching mencoba untuk mengelompokkan informasi terkini ke dalam beberapa gathering, dimana informasi dalam satu gathering memiliki atribut yang sama satu sama lain dan memiliki berbagai kualitas dari informasi pada gathering yang berbeda.Adapun tahapantahapan dalam metode $k$-means adalah:

1. Tentukan jumlah kelompok yang perlu Anda buat.

2. Perkenalkan k sebagai centroid yang dapat dibuat sewenang-wenang.

3. Hitung jarak setiap informasi ke setiap centroid dengan menggunakan kondisi Euclidean Distance.

4. Mengumpulkan setiap informasi tergantung pada jarak terpendek antara informasi dan pusatnya.

5. Tentukan situasi centroid baru $(\mathrm{k})$.

6. Kembali ke tahap 3 jika situasi centroid baru dengan centroid lama tidak terlalu mirip.

\section{Hasil dan Pembahasan (Results and Discussions)}

Data diambil atau scrap dari e-commerce shopee.co.id selanjutnya akan dilakukan pre-prosesesing antara lain: cleaning, remove stopword, tokenization steming.

\subsection{Pre-Prosesesing}

\section{a. Cleaning}

Ialah proses penghapusan tanda baca(punctuation), symbol, huruf besar (uppercase) manjadi huruf kecil (lowercase) serta bilangan angka(numbers). Sehingga data tersebut menjadi data yang efektif serta dapat diolah dengan baik.

\section{b. Remove Stopword}

Ialah sebuah proses menghapus (kata-kata) yang kurang penting atau words yang tidak penting misalnya kata dan, atau, kamu, aku.

\section{c. Tokenization}

Ialah Metode yang terlibat dengan memecah kalimat menjadi beberapa bagian dikenal sebagai token. Token dapat dianggap sebagai jenis kata, ekspresi, atau komponen yang memiliki makna.

\section{d. Stemming}

Ialah cara paling umum untuk mengubah kata ke dalam struktur dasarnya dengan menghilangkan gabungan sebelumnya, kemudian setelah kata itu. 


\subsection{Hasil dan analisis Word cloud}

Word cloud ataupun biasa disebut juga dengan text cloud merupakan satu dari beberapa metode untuk menampilkan data teks secara visual. Metode ini sangat banyak digunakan dan popular terutama untuk teks minning. Berikut ialah hasil dari proses analisis teks word cloud.

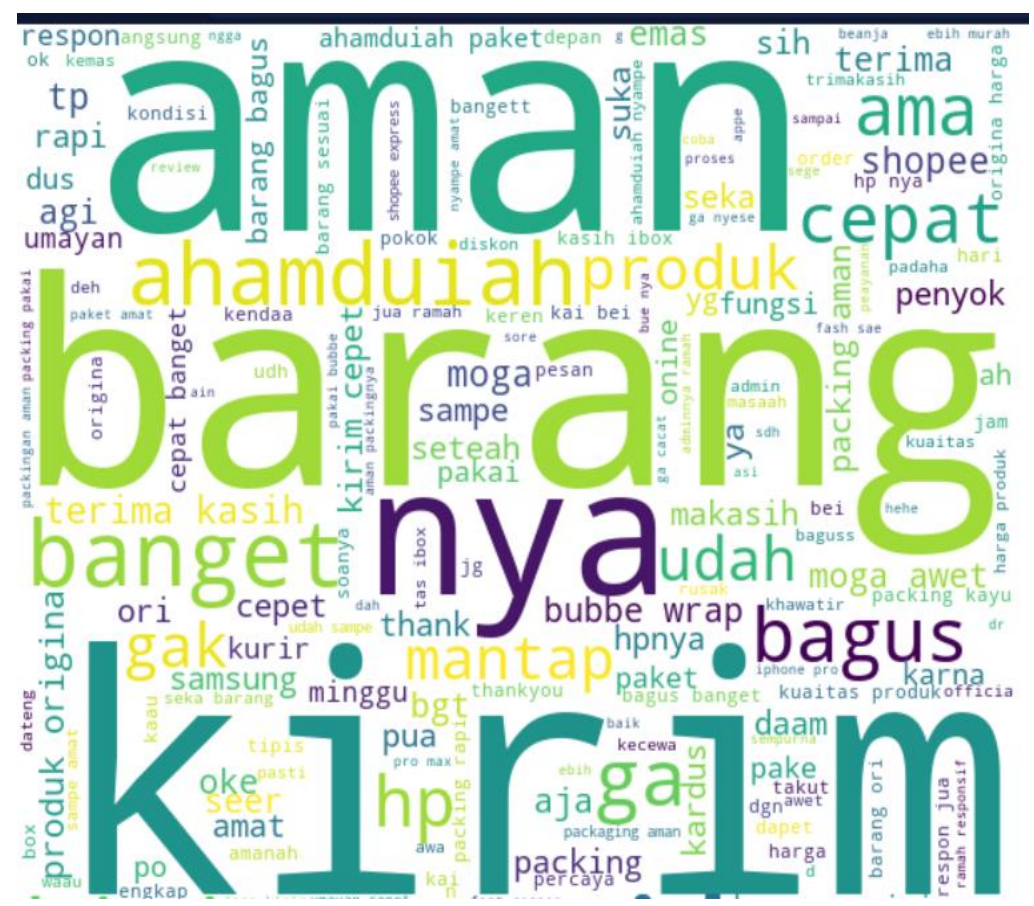

Gambar 3.1 Output dari proses word cloud smartphone jenis low cost

Dari Word cloud graphics diatas nampak kata dominan adalah aman, barang dan kirim, beberapa kata yang lebih kecil muncul antara lain cepat, bagus, cepet, penyok, dan terima. Nampak juga beberapa kata yang bermakna negatif seperti penyok, takut, dan setengah pakai hanya muncul dengan format huruf yang kecil yang berarti tidak mendominasi teks. Sedang kata-kata yang dominan cenderung netral atau positif seperti barang, kirim, aman dan bagus.

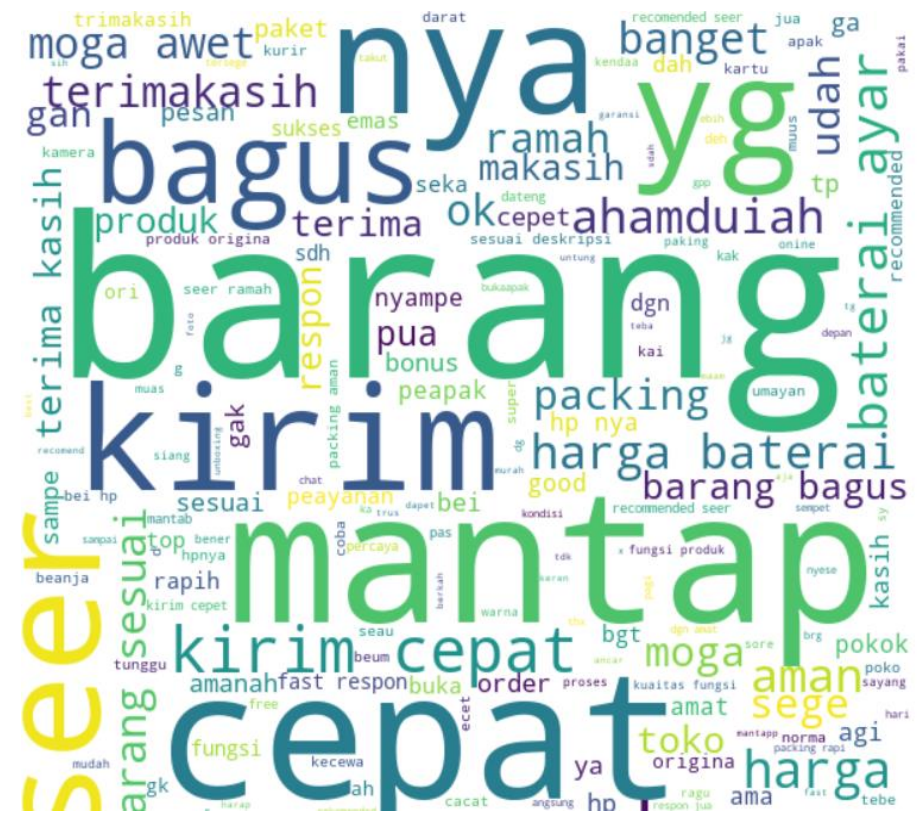

Gambar 3.2 Hasil atau output dari proses word cloud smartphone jenis high cost 
Berdasarkan hasil proses word cloud smartphone jenis high cost pada gambar di atas menunjukan bahwa kata yang dominan sering muncul pada ialah kata barang, mantap, cepat,kirim dan bagus. Sebagian cenderung kata-kata netral dan positif. Sementara kata-kata yang bermakna positif banyak muncul namun tidak dominan misalnya kata kirim, cepat, ramah, bagus banyak muncul di format teks yang kecil artina tidak terlalu mendominasi komentar. Sedangkan kata yang negatif hampir tidak nampak pada wordcloud.

\title{
3.3 K-Means Clustering
}

Analisis clustering dilakukan pada data penjualan dan rating yang diperoleh pada setiap item barang smartphone yang ditarik dari e-commerce. Berikut proses dan hasil analisis $K$-Means dengan python untuk data rating dan angka penjualan pada smartphone low cost.

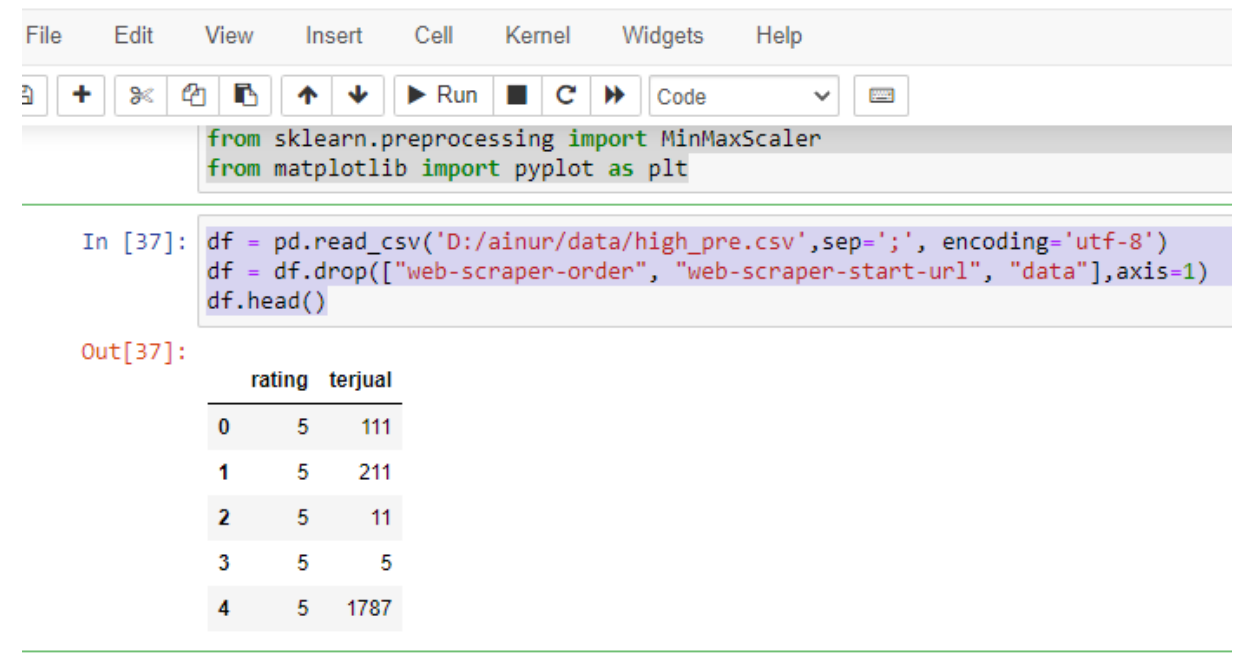

Gambar 3.3 Code import library dan hasil atau output data

Dari data di atas untuk smartphone low cost nampak bahwa angka penjualan baik yang rendah maupun yang tertinggi cenderung memiliki cluster yang sama dengan kecenderungan sama memperoleh rating 5 dari pelanggan.

\#data info

Data.info()

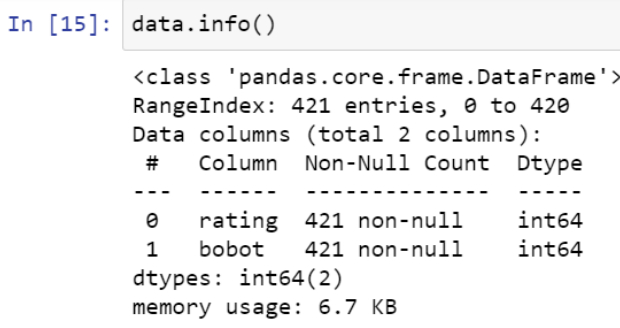

Gambar 3.4 Melihat informasi data atau data info

\author{
Sebaran data \\ \#sebaran data \\ plt.scatter(df.rating,df['terjual']) \\ plt.xlabel('Rating') \\ plt.ylabel('Terjual')
}



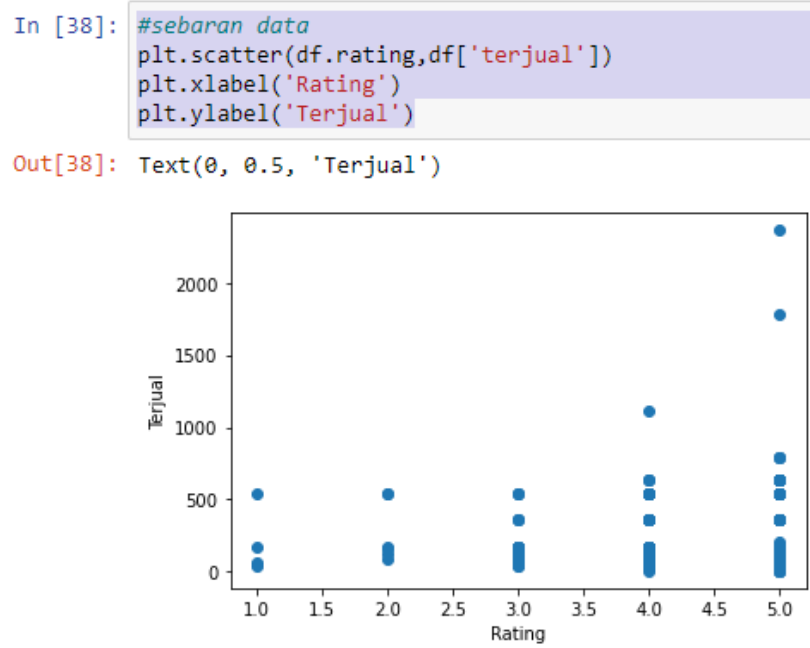

Gambar 3.5 Proses melihat sebaran dan hasil (output)

\section{k-means prediksi}

df['cluster']=y_predicted

df.head(10)

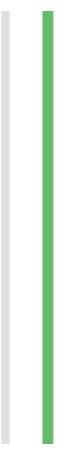

\section{Gambar 3.6 hasil prediksi}

Dari data di atas untuk smartphone high cost juga nampak tidak ada perbedaan dimana angka penjualan baik yang rendah maupun yang tertinggi cenderung memiliki cluster yang sama dengan kecenderungan sama memperoleh rating 5 dari pelanggan, meskipun terdapat cluster yang berbeda untuk angka penjualan yang tertinggi.

Selanjutnya analisis clustering untuk data yang di scrap baik data smartphone yang high cost maupun yang low cost diperoleh hasil sebagai berikut.

\# Visualisai clustering. 
Out[42]: 〈matplotlib.legend. Legend at 0x18e9b8dd100〉

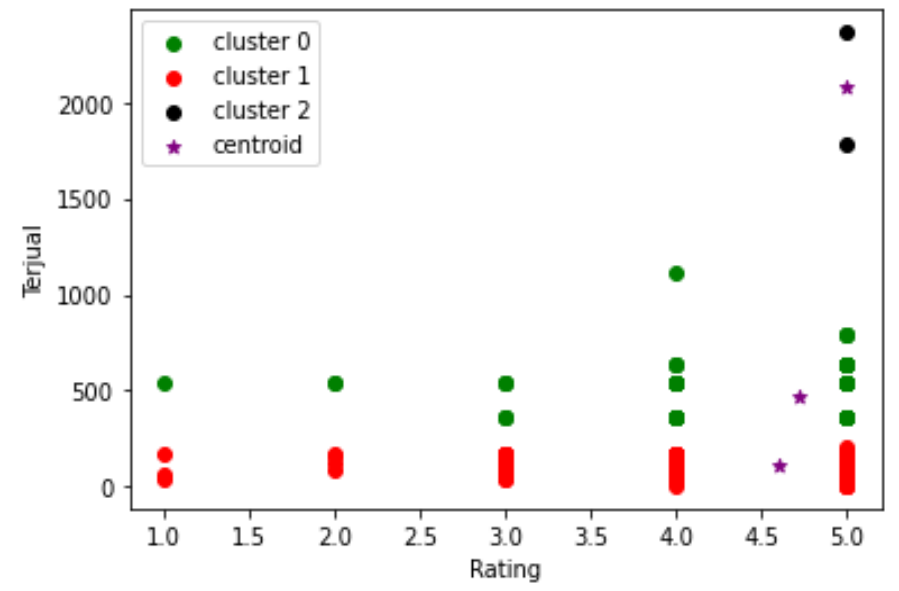

Gambar 3.7 proses dan hasil output 3 cluster data seluruh smartphone

Berdasarkan hasil grafik dari proses clustering di atas menunjukan bahwa angka penjualan 0 sampai 1000 mendapatkan rating tertinggi.

Keterangan:

1. Warna bintang ungu berarti menunjukan titik pusat atau lokasi cluster yang biasa di sebut juga centroid.

2. Warna hijau merupakan cluster pertama atau cluster 0 dikarenakan di python angka dimulai dari 0 dan murupakan cluster dengan nilai sedang.

3. Warna merah merupakan cluster kedua atau cluster 1 dan merupakan cluster dengan nilai tertinggi.

4. Warna hitam cluster ketiga atau claster 2 dan merupakan cluster dengan nilai terendah.

\section{Kesimpulan (Conclusion)}

Berdasarkan uraian pada bab sebelumnya serta dari hasil proses analisis pengelompokan teks selesai pada keterangan pusat niaga shoppe Indonesia, didapatkan beberapa kesimpulan:

1. Berdasarkan data komentar marketplace shopee Indonesia dapat bahwa baik di smartphone low cost maupun yang high cost cenderung memiliki pola wordloud yang sama dimana kata-kata yang dominan muncul cenderung netral dan positif, sedang kata-kata yang bermakna negatif cederung tidak dominan.

2. Hasil analisis clustering cenderung diperoleh tidak ada beda antara angka penjualan dengan rating yang diperoleh baik untuk produk smartphone high level maupun low level.

3. Dari proses clusterisasi menggunakan k-means terdapat 3 cluster yaitu cluster pertama(0) ditunjukan dengan warna hijau, cluster kedua(1) dengan warna merah serta cluster ketiga(2) dengan warna hitam . Warna bintang ungu berarti menunjukan titik pusat cluster atau menunjukan titik centroid nya.

\section{Ucapan Terima Kasih (Acknowledgement)}

Penulis menyampaikan terima kasih sebesar-besarnya kepada seluruh tim atas kerja bersamanya, khususnya untuk Bapak Heri Suroyo, beliau merupakan dosen pembimbing kami yang telah memberikan saran, bimbingan serta referensi untuk publikasi di jurnal ini.

\section{Daftar Pustaka}

A. Yani,D.D., Pratiwi, H. S., \& Muhardi, H. (2019). Implementasi Web Scraping untuk Pengambilan Data pada Situs Marketplace. Jurnal Sistem Dan Teknologi Informasi (JUSTIN), 7(4), 257. https://doi.org/10.26418/justin.v7i4.30930 
Handoyo,R., Rumani,R., \& Nasution,S.M. (2014). Perbandingan Metode Clustering Menggunakan Metode Single Linkage Dan KMeans Pada Pengelompokan Dokumen. JSM STMIK Mikroskil, 15(2), 73-82. https://mikroskil.ac.id/ejurnal/index.php/jsm/article/view/161

Sentiya, A., Suroyo, H., Komputer, F. I., \& Darma, U. B. (n.d.). bina darma conference on computer science ANALISIS TEXT CLUSTERING AKUN FANPAGE SHOPEE INDONESIA DENGAN bina darma conference on computer science. 1055-1067.

Hasibuan A, Z. (2007). Metodologi Penelitian Pada Bidang Ilmu Komputer Dan Teknologi Informasi, $4(1), 1-194$.

Jony Wong, W. (2008). Belanja Elektronik. Belanja Elektronik, 10-42.

Syaifudin, Y. W., \& Irawan, R. A. (2018). Implementasi Analisis Clustering Dan Sentimen Data Twitter Pada Opini Wisata Pantai Menggunakan Metode K-Means. Jurnal Informatika Polinema, 4(3), 189. https://doi.org/10.33795/jip.v4i3.205

Indraloka, D. S., \& Santosa, B. (2017). Penerapan Text Mining untuk Melakukan Clustering Data Tweet Shopee Indonesia. Jurnal Sains Dan Seni ITS, 6(2), 6-11. https://doi.org/10.12962/j23373520.v6i2.24419 
Halaman ini sengaja dikosongkan 